\section{Expressões da sexualidade e de gênero na injunção crime-loucura: engendramentos moralizantes no tratamento do paciente judiciário}

\author{
Expressions of sexuality and gender at the \\ interface between crime and madness: \\ moralizing conceptions in the treatment \\ of the "criminally insane" patient
}

\section{Expresiones de sexualidad y género en procedimientos judiciales relacionados con casos de crimen-locura: sentencias moralizadoras en el trato a pacientes judiciales}

Willian Guimarães 1

Simone Mainieri Paulon 1

Henrique Caetano Nardi 1

doi: 10.1590/0102-311X00180317

\section{Resumo}

Este artigo tem por objetivo analisar a forma como as expressões da sexualidade e de gênero emergem nos trâmites judiciais que definem os destinos dos sujeitos na injunção crime-loucura. Para isso, explora os processos penais referentes às pessoas em sofrimento mental que cometeram crimes, os chamados pacientes judiciários, que recebem uma medida de segurança. Utilizando-se da genealogia como aporte metodológico, adentra-se nas condições de proveniência e de emergência do "anormal", figura produzida e esquadrinhada pelo discurso médico-jurídico. Foram analisadas seis peças judiciais, focando principalmente os laudos psiquiátricos de pessoas não heterossexuais e/ou não cisgêneras que receberam uma medida de segurança. A análise do córpus indica que a base teórico-conceitual na qual se sustentam os pressupostos da medida de segurança se concentra no laudo psiquiátrico. A análise do discurso médico-jurídico aponta para uma valoração moral das expressões da sexualidade e de gênero do paciente judiciário considerado "desviante". Por fim, sinalizamse alternativas de produção de novos modelos de tratamento para o paciente judiciário, que buscam superar a ficção da presunção de periculosidade como base pretensamente científica, revisando a inimputabilidade como dispositivo jurídico que viola direitos inalienáveis dos sujeitos na injunção crime-loucura.

Desinstitucionalização; Sexualidade; Identidade de Gênero; Saúde Mental; Direitos Humanos

\author{
Correspondência \\ W. Guimarães \\ Universidade Federal do Rio Grande do Sul. \\ Rua Ramiro Barcelos 2600, Porto Alegre, RS 90035-003, Brasil. \\ willgaspar@gmail.com \\ 1 Universidade Federal do Rio Grande do Sul, Porto Alegre, \\ Brasil.
}


A associação loucura e periculosidade foi construída na modernidade 1. Quando uma pessoa diagnosticada com transtorno mental comete um crime, o caminho legal é de que seja avaliada por um perito, por indicação judicial, para estabelecimento de laudo que ateste sua capacidade de entendimento do delito cometido. Instaurado o incidente de insanidade mental, essas pessoas podem ser consideradas incapazes de responder por suas infrações legais. Nesse caso, os sujeitos recebem não uma pena alternativa ou privativa de liberdade, mas uma medida de segurança e são encaminhados para tratamento ambulatorial em serviços de saúde mental ou, como acontece na maioria das vezes, são internados em hospitais de custódia, os conhecidos manicômios judiciários. Em vez de uma pena comum em prisão, esse sujeito recebe um tratamento como forma de averiguar e conter a periculosidade que a sociedade lhe atribui. Supostamente, o sujeito com transtorno mental deveria ter um atendimento mais singularizado do que no regime prisional. Sua liberdade está condicionada à cessação do perigo, algo que é julgado por um perito e que não é mais vinculado ao crime, mas ao sujeito criminoso.

A violação dos Direitos Humanos, propiciada pela medida de segurança, é ainda mais gritante quando posta em contraste seus efeitos com o que se espera de uma medida de tratamento humanizado a pessoas em sofrimento mental. A Lei no 10.216/20012, chamada de Lei da Reforma Psiquiátrica, preconiza o redirecionamento do modelo assistencial em saúde mental para o atendimento na rede de atenção psicossocial. Esse código jurídico busca alterar o modelo clássico de atendimento que centraliza a ação terapêutica na internação hospitalar.

A magnitude da importância dessa questão foi demonstrada pelo Censo Estabelecimentos de Custódia e Tratamento Psiquiátrico de 2011 3, coordenado por Debora Diniz, que levanta, entre outras informações, dados sobre a internação de sujeitos com medida de segurança em 26 estabelecimentos de custódia e tratamento psiquiátrico em 19 estados e no Distrito Federal. Dos 3.989 indivíduos nessas instituições, $41 \%$ estão com o laudo de cessação de periculosidade atrasado; $24 \%$ têm indicação positiva para a cessação e continuam cumprindo a medida; $21 \%$ estão internados há mais tempo do que a pena máxima para a infração cometida. Dentre essas, 18 pessoas estão internadas há mais de trinta anos, e três pessoas em medida de segurança sem qualquer processo judicial 3. Com objetivo semelhante, em 2015, o Conselho Federal de Psicologia (CFP), em conjunto com o Conselho Federal da Ordem dos Advogados do Brasil (OAB) e da Associação Nacional do Ministério Público em Defesa da Saúde (AMPASA), realizou uma inspeção nacional aos manicômios judiciários e alas psiquiátricas similares em 17 estados e no Distrito Federal. Foram 18 unidades pesquisadas, que comportavam naquele momento 2.864 presos/pacientes, sendo 964 inimputáveis, 28 semi-imputáveis e $490 \mathrm{em}$ internação temporária (aguardando exame de sanidade mental ou exame de cessação de periculosidade, ou seja, não deveriam estar ali ainda). Dos 1.131 profissionais que atuam nesses estabelecimentos, 611 são agentes de segurança. Mais da metade dos profissionais não são preparados especificamente para atuar no regime prisional. Sete dos estabelecimentos estão com superlotação que varia de $110 \%$ da capacidade de vagas instaladas a 410\%. A situação jurídica é ainda mais problemática, pois em apenas $17 \%$ dos casos relatados o prazo anual de realização do exame de cessação de periculosidade é cumprido. Sendo esse um estabelecimento do regime prisional, chama atenção que nenhuma das equipes periciais conta com a presença de um advogado 4 . Esses dados demonstram o contexto precário e de desrespeito aos direitos humanos, ofertado a essas pessoas que necessitam de um atendimento em saúde mental especializado.

Estar inscrito na injunção crime-loucura ressalta uma série de traços nesses sujeitos que têm sido, historicamente, pelo crivo do saber médico e jurídico, considerados desviantes. As expressões da sexualidade e de gênero que não correspondem à cisheteronorma, quando estão presentes na injunção crime-loucura, acentuam uma já existente moralização desses corpos. Estabelece-se essa suposição com base na existência de um estigma associado a pessoas não heterossexuais e não cisgêneras, que é intensificado quando estes sujeitos estão diretamente à mercê do discurso médico-jurídico.

A lógica manicomial opera no campo da sexualidade e do gênero de diferentes formas de higienização da sociedade, ao mesmo tempo em que reafirma a imoralidade daqueles que transgridem a expectativa imputada a estas expressões. Austregésilo Carrano Bueno, na obra $O$ Canto dos Malditos 5 , que deu origem ao filme Bicho de Sete Cabeças, descreve a rotina institucional de suas internações em diversos manicômios, evidenciando que, sob uma aparência curativa, o que de fato oferecem são as mais diversas formas de violência e exclusão. Carrara 6 descreve a tentativa dos pacientes do Manicômio Judiciário Heitor Carrilho, no Rio de Janeiro, de ter um parlatório, um local para receber seus 
parceiros sexuais, o qual foi prontamente negado pela equipe de atendimento em função do suposto perigo que a reserva de um lugar deste tipo poderia ocasionar. Ibrahim ${ }^{7}$ relata a violência institucional que se abate na divisão do espaço funcional do manicômio judiciário, no qual as mulheres devem permanecer isoladas dos homens sem o acesso livre aos espaços abertos da instituição. Jacobina 1 afirma que o manicômio abrigou e ainda abriga todos os tipos de sujeitos que cometeram uma variedade extensa de crimes, sendo que o único fato que os une é serem considerados seres desajustados socialmente.

Ao colocar em discussão as práticas sobre o gênero e a sexualidade na injunção crime-loucura, tem-se por objetivo evidenciar as racionalidades que produzem e mantêm determinados engendramentos moralizantes sobre o corpo do paciente judiciário. Não se busca propor outra racionalidade sobre a loucura ou outros modos de gerir os "loucos infratores", mas evidenciar os diferentes jogos de verdade que constroem uma suposta identidade atemporal e a-histórica para essas pessoas, especialmente quando a sexualidade ou o gênero entram em cena. Ao problematizar essas práticas, deseja-se reconhecer a constituição de um modo de ser sujeito que é atravessado por diferentes discursos, contextualizados em cada época, que convocam os sujeitos a se reconhecerem e se relacionarem consigo ${ }^{8}$. A naturalização desses jogos de verdade evidencia a eficácia de sua própria manutenção, um modo de conceber o "louco criminoso" como uma substância fechada em si mesma que não se relaciona com o seu tempo.

\section{O louco infrator e sua relação com a norma}

Afirmar que a figura do "louco criminoso" não é atemporal significa dizer que esta tem uma história. Ao longo do tempo, foi necessário classificá-lo, catalogá-lo enquadrá-lo em nosologias por meio da articulação de dispositivos que dessem conta de descrever e ordenar essa figura. Essa forma de conceber o dito "louco" que emerge da injunção crime-loucura, do encontro entre os campos de conhecimento do Direito e da Psiquiatria, é produto de uma série de procedimentos jurídicos de punição que se deram na Idade Medieval sobre os "desviantes" até a formação gradual de um saber em consonância com um poder de normalização em que se produz aquele que se entende por "anormal" 9.

O "anormal" é um efeito de diferentes embates dos saberes jurídicos e de um longo processo da psiquiatrização do desejo e da sexualidade que ocorreu de forma gradativa durante o século XIX. Não é a prisão o destino do "louco", mas o hospital. Não é apenas punido, precisa ser tratado. O psiquiatra se efetiva como aliado do juiz, ao mesmo tempo em que o juiz se desdobra em um mecanismo médico. O "médico-juiz" não julga o sujeito jurídico com base na infração definida por uma lei, mas impõe a este indivíduo uma série de medidas corretivas, de readaptação, de reinserção. Configura-se o continuum médico-judiciário. "O duro ofício de punir vê-se assim alterado para o belo ofício de curar. $E$ a essa alteração que serve, entre outras coisas, o exame psiquiátrico" 9 (p. 29). O controle pormenorizado do dito louco vai gradativamente se tornar a ação central do dispositivo médico-jurídico. Altera-se o paradigma da responsabilidade. Em vez de apenas punir, a sanção penal se ocupa em curar e readaptar.

A sustentação desse mecanismo se dá pela reativação de categorias elementares da moralidade, discursos que se organizam em torno da noção de perversidade, do medo e do perigo social. Logo, esses mecanismos surgem para detectar e combater essas anomalias. Fica estabelecido o limite da normalidade, suas gradações e o ponto-limite onde irá residir o anormal, não somente para marcar sua existência, mas para estabelecer uma forma de controle sobre ele.

O efeito do encontro entre o saber médico e o poder judiciário facilita a emergência do que Foucault chama de poder de normalização, que se valerá de uma autonomia própria frente às instituições que o produzem. Esse mecanismo apenas se efetiva pela reativação de categorias elementares da moralidade-cientificidade: técnicas médico-jurídicas que se organizam em torno das concepções de perversidade e do perigo com base na produção de um discurso essencialmente parental-pueril, que se vale do medo e da moralização da loucura ${ }^{9}$.

A partir da metade do século XIX, essa dupla qualificação médico-judiciária organizou todo um domínio da "perversidade" que orientou o discurso dos peritos para uma linguagem que ressaltou elementos considerados caducos, ridículos e pueris. Tal linguagem serviu como ponte entre as categorias jurídicas definidas pelo próprio código penal e as noções médicas que atestaram o atraso, defeito 
ou incompletude no desenvolvimento desse sujeito. A concepção de perversidade uniu uma infração jurídica a uma falha psicológica-moral baseando-se no exame psiquiátrico. Os efeitos dessa articulação se alastraram de forma gradativa por todo campo social.

No campo dos estudos de gênero, Butler 10 problematiza o processo de normalização, valendo-se do que entende como matriz heterossexual, ou seja, a naturalização do alinhamento identitário entre sexo-gênero-desejo. Tal produção discursiva aponta para a heterossexualidade e a cisgeneridade como padrão esperado de normalidade, colocando em análise um corpo construído e traçado pelas formações discursivas calcadas nas expressões heterossexuais ou cisgêneras. Para garantir a permanência da norma, são realizados investimentos em múltiplas instâncias: a família, a escola, as leis, a mídia, a ciência. Essas normas regulatórias estabelecem limites de legitimidade, de sanidade e de moralidade, e aqueles que as transgridem têm seu corpo marcado e seu status de sujeito alterado para ilegítimo, imoral e patológico. Conhecimentos científicos tendem a reiterar as normas regulatórias construtoras da materialidade dos corpos, negando a existência daqueles que não atendem aos preceitos normativos. Em última análise, o que está em questão são as relações de poder como entidade difusa, dispersa e indeterminada. São elas que atravessam os dispositivos sociais utilizados para controlar e vigiar corpos dóceis.

$\mathrm{Na}$ busca de certa racionalidade para os crimes ditos irracionais, o aparelho penal articula com o saber psiquiátrico formas de tornar inteligível aquilo que até então escapa à explicação da lei. Ungido de uma racionalidade científica, o campo da Psiquiatria, diante dessa demanda do judiciário, opera duas importantes codificações: (1) a codificação da loucura e demais desvios com base em um quadro específico de análises, que os consideram patologias; (2) a codificação da loucura como portadora de um perigo possível que necessita de controle 9. A partir do século XIX, a Psiquiatria pôde se qualificar, ao mesmo tempo, como campo de saber científico sobre a doença mental e como ramo da higiene pública que combate o perigo em potencial em cada "desviante". A ação da Psiquiatria aconteceu simultaneamente no manicômio pelas técnicas de governo da loucura, e em seu exterior pela busca do perigo em cada pequeno ato desarrazoado no campo social.

$\mathrm{O}$ exame psiquiátrico em matéria penal se estabelece como ferramenta desse campo na mesma medida em que seus efeitos se efetivam na sociedade. Para construir uma determinada inteligibilidade do crime, a Psiquiatria vai se voltar para as falhas na história do sujeito como forma de imputá-lo uma infração moral. A partir da codificação de infrações ético-psicológicas em delitos, a trajetória de vida dessas pessoas é circunscrita à injunção crime-loucura.

\section{A metodologia genealógica e a incursão no arquivo judiciário}

O presente trabalho visa a adentrar a injunção crime-loucura, problematizando os efeitos de verdade produzidos sobre o paciente judiciário. No que tange à sua exploração, utiliza-se de uma abordagem metodológica que é a genealogia. Uma investigação genealógica visa à elaboração de diagramas que, problematizando e causando estranhamento sobre aquilo que se assenta como verdade, apresente as condições políticas de possibilidade dos discursos. Como forma de operar essa metodologia, citam-se dois procedimentos: a análise da proveniência e a análise da emergência. A primeira aponta para a descoberta de marcas sutis da singularidade e seus intercruzamentos, a segunda envolve a preocupação com os vetores de força que marcam o aparecimento de um costume. Ambas apontam para as descontinuidades e rupturas que atravessam os discursos 11. Além disso, um importante operador metodológico que norteia esta pesquisa é a noção de dispositivo como a reunião de um conjunto heterogênio de elementos, dentre os quais estão discursos, instituições, leis, medidas administrativas, enunciados científicos, proposições filosóficas e morais ${ }^{12}$. Entende-se esse operador como essencial para compreender os efeitos que os jogos de saber-poder produzem na injunção que esta pesquisa busca analisar.

O desenho deste trabalho foi organizado em torno da análise de casos de pessoas não heterossexuais e não cisgêneras, que receberam uma medida de segurança de internação, cujas peças processuais pudessem ser consultadas. Foi feita essa escolha pela importância que assumem tais documentos ao operarem discursos de verdade que afetam diretamente a vida do "louco infrator". Para Scaramella 13, as peças judiciais compõem o que chama de narrativas biográficas judiciárias, uma 
vez que compactam mais do que fatos, sintetizam vidas e tempos. Operam uma lógica particular de atribuir um sentido único à história dos sujeitos, dando-lhes uma determinada coerência que os liga ao crime cometido.

Para tal compreensão, centra-se a análise nos laudos psiquiátricos, compreendendo que estes documentos são determinantes na configuração de uma medida de segurança. A avaliação empreendida pelo perito é um dos efeitos da produção científica que se deteve na busca de um marcador biológico do perigo da loucura, fazendo do sujeito desviante objeto de ação dos dispositivos do biopoder. Para Barros-Brisset 14, as teorias de Pinel, Morel e Lombroso que marcaram o "louco" pelo seu déficit moral abriram espaço para que o exame médico-penal se tornasse ferramenta privilegiada de detecção e contenção dos "anormais". A busca para extirpar o "mal" e o perigo em potencial em cada delinquente proposta por essas teorias é o terreno de fundação de uma orientação científica positivista, que considera uma natureza patológica anterior ao delito ${ }^{14}$. A substituição do crime pela doença organiza uma determinada lógica de intervir sobre o desviante.

Ao investigar os arquivos produzidos pelo judiciário, com centralidade nos arquivos da Vara de Execução de Penas e Medidas Alternativas (VEPMA) do Tribunal de Justiça do Rio Grande do Sul (TJRS), órgão jurídico que atua diretamente na questão do crime-loucura no estado, objetivamos averiguar como os corpos ditos desviantes da cisheteronormatividade entram em cena nessas produções. A ferramenta de busca de processos do judiciário apenas permite encontrar casos, com base no número do processo de execução criminal (PEC) ou pelo nome do sujeito, logo, foi necessário recorrer a diferentes operadores do Direito e da Saúde Mental para encontrar casos que se enquadravam no crivo solicitado.

Decidiu-se por elencar algumas pessoas que ocupavam lugares institucionais estratégicos para questioná-las acerca de processos nos quais a sexualidade e o gênero dos réus, julgados como desviantes, apareciam como fator na injunção crime-loucura. Dentre os possíveis entrevistados, com base nesse critério, foram escolhidos: (1) o juiz atual da Vara em questão; (2) a advogada que é assessora deste juiz; (3) uma das psicólogas que atua no Foro Central junto a esta Vara; (4) uma assistente social que atua no manicômio judiciário; (5) um psiquiatra que realiza os exames médico-legais e acompanha casos de medida de segurança no manicômio judiciário.

Baseando-se no diálogo com esses operadores, foram selecionados seis casos de pessoas com "sexualidade ou gênero desviantes", ou seja, não heterossexuais ou não cisgêneras que se tornaram foco de observação e análise desta pesquisa. Dos seis casos, quatro se tratavam de homens cis, um caso de uma mulher cis e um caso de uma mulher travesti. Para a produção deste artigo, foram escolhidos alguns fragmentos dos laudos psiquiátricos emitidos sobre essas pessoas. O recorte realizado perpassa o olhar dos operadores do Direito e da Saúde Mental referido anteriormente, com base em suas memórias e experiências junto à temática desta pesquisa.

Este trabalho foi submetido ao Comitê de Ética em Pesquisa do Instituto de Psicologia da Universidade Federal do Rio Grande do Sul com o CAAE: 62005016.0.0000.5334 e foi aprovado sob o Parecer Consubstanciado de no 1.876 .222 . A pesquisa de campo foi realizada entre abril e junho de 2017. Todas as informações que permitem a identificação de pessoas ou instituições foram ocultadas.

\section{O laudo psiquiátrico e a inteligibilidade das expressões da sexualidade e de gênero}

Os documentos de uma peça processual não são estáticos e revelam diferentes disputas entres os operadores. Observada na investigação das peças, após o estabelecimento da medida de segurança, há uma dinâmica bem específica entre o perito psiquiatra, a promotoria, a defesa do sujeito e o juiz. Ao fim do prazo estipulado para a medida de segurança, o juiz requer um novo exame médico-legal que deve atestar a cessação da periculosidade. Com base na resposta negativa da cessação de periculosidade, via de regra, a promotoria sugere a continuidade da medida de segurança. A defesa pede a revogação da medida de segurança. Por fim, o juiz, em geral, nega o pedido da defesa, entendendo que o laudo do psiquiatra é definitivo e prorroga a medida de segurança por mais 1 a 3 anos. Ao fim desse prazo, esse ciclo é repetido. A pessoa que recebe uma medida de segurança permanece nesse ciclo na dependência de um laudo técnico que vai afirmar se poderá retornar ao convívio social. Isso apenas é alterado caso o exame indique que a periculosidade está cessada. Nesse momento, o juiz decreta a 
liberdade condicional do sujeito por um ano. A custódia judicial apenas encerrará definitivamente caso não haja algum incidente que indique a permanência de presunção de periculosidade.

Dentre os diversos documentos que uma peça jurídica pode conter, no caso do paciente judiciário, os laudos psiquiátricos têm importância central. É o documento que pode bifurcar o destino de uma pessoa para longe da prisão comum e colocá-la, quiçá perenemente, em um manicômio judiciário. Trata-se de um parecer escrito por profissionais do campo da Psiquiatria que respondem a uma determinada requisição judicial, averiguando, com base em um conhecimento científico específico, a capacidade de compreensão de um sujeito diante do crime que cometeu. É também por meio do mesmo laudo que um juiz decidirá se a pessoa deverá ou não continuar presa por tempo indefinido, com base na presunção de periculosidade social. Contudo, o princípio norteador que orienta esse documento produz, na verdade, a concepção de que tudo que escapa a uma determinada racionalidade hegemônica é perigoso e deve ser excluído do convívio social.

O laudo psiquiátrico é um dos documentos em que é possível evidenciar os efeitos do continuum médico-judiciário, pois por meio dele circula uma determinada racionalidade científica que embasa as ações da justiça. Há um modelo epistemológico de ciência que sustenta essas práticas, baseando-se em uma crença de que os mecanismos científicos podem revelar a verdade última sobre a realidade social 15 .

O diagnóstico imputado pelo psiquiatra bifurca o destino do paciente judiciário. Como já afirmado, a loucura e a responsabilidade penal pelo crime tornam-se incompatíveis. "Princípio de porta giratória: quando o patológico entra em cena, a criminalidade, nos termos da lei, deve desaparecer" 9 (p. 27). A concepção de perigo substitui uma sanção temporal com prazo determinado por um tratamento que deve dar conta das condições mentais consideradas deficitárias daquele sujeito.

Segundo Foucault 9, os discursos utilizados por dispositivos jurídico-psiquiátricos são dotados de três características: (1) têm o poder de decidir o destino de vida ou morte de alguém; (2) seu poder vem da instituição judiciária, pautado em um suposto estatuto de verdade e ciência; (3) são discursos que fazem rir. Por se tratar de um discurso com características tão emblemáticas, entende-se a importância de problematizar sua construção e seus efeitos ao longo do tempo.

A produção da subjetividade não está descolada do processo de produção da sexualidade e de gênero. Quando se diz que o "louco" não heterossexual ou não cisgênero é considerado desviante, reafirma-se a matriz cultural cisheteronormativa que opera sob uma lógica binária, tendo a heterossexualidade e a cisgeneridade como ponto de partida da normalidade 10 . Logo, há aqueles que estão à margem dessa, os considerados abjetos, seres a quem a inteligibilidade de seus corpos só pode emergir no avesso da norma. Ao estar em desacordo com essa matriz, a inteligibilidade do corpo do "louco" será considerada abjeta e estará ao alcance das técnicas disciplinares para seu controle.

"Trata-se de um travesti envelhecido, feio, figura patética. Porta-se, entretanto, de forma coquete e sedutora, tentando envolver e angariar a simpatia e a piedade dos peritos. Lamenta-se constantemente, queixa-se da vida $e$ de todos, mas deixa transparecer um certo orgulho por ser 'tão' perseguido, 'tão' sofrido e 'tão' infeliz. (...) A linguagem é efeminada, afetada, prolixa. Apresenta conduta delinquente e antissocial, homossexualismo, transvestismo e crises histéricas extremamente bizarras e de tal forma dramáticas que sugerem um surto psicótico. (...) Não se mudará suas características de personalidade, ainda que se tente investir todas as formas de tratamento conhecidas da medicina" (laudo psiquiátrico sobre mulher travesti, 23/Dez/1991).

$\mathrm{O}$ fragmento de um laudo exposto anteriormente descreve a sexualidade e o gênero de um paciente judiciário, utilizando uma escrita com diversos adjetivos pejorativos. A própria redação do exame quer elucidar a depravação psicológica-moral do examinado. Para descrever o sujeito, são usados adjetivos que desrespeitam a expressão de gênero dessa pessoa, assim como de seus comportamentos e características pessoais no relacionamento com os técnicos do Hospital de Custódia. Mesmo quando tenta utilizar a linguagem diagnóstica típica da psiquiatra, o perito elabora enunciados problemáticos e depreciativos como "homossexualismo" (não mais presente na Classificação Internacional de Doenças - CID - e no Manual Diagnóstico e Estatístico de Transtornos Mentais - DSM - à época do laudo) e "transvestismo".

A normalização, operando por meio da linguagem, produz corpos e sujeitos na reiteração de uma materialidade, constrangendo-os e limitando-os, tendo compulsoriamente a heterossexualidade como padrão 10 . O dispositivo médico-jurídico opera valendo-se desses engendramentos para produzir o esquadrinhamento do sujeito na injunção crime-loucura. 
Sujeitos como os descritos por esse exame são objeto de uma moralização de suas condutas. Ao estar em desacordo com a matriz cisheteronormativa, a inteligibilidade do corpo do "louco" será considerada imoral e estará ao alcance das técnicas disciplinares para seu controle. A descrição apresentada pelo perito narra uma perspectiva de acompanhamento que centra sua incursão na busca de traços patológicos, para justificar a internação hospitalar. Modelo produzido em momento anterior à homologação da Lei da Reforma Psiquiátrica, este reforça a institucionalização como via central para $\mathrm{o}$ atendimento à pessoa em sofrimento mental.

O exame médico-legal demarca o território existencial dos seres abjetos. Ao ter seus direitos básicos revogados, o "louco infrator" circunscreve os alcances da lei para os sujeitos de direito, como também comunica o que pode acontecer com quem ousar cruzar a fronteira da normalidade 10. É a confirmação de irracionalidade que nega seu status de ser humano. Essa tecnologia específica de poder utiliza esses discursos legitimados por um dado jogo de verdades sobre o sujeito na injunção crime-loucura, como se pode observar no fragmento a seguir:

"Mostra-se dramático e teatral na sua conduta homossexual que chega a ser bizarra da qual não tem crítica alguma. (...) A conduta é bizarra, marcada por trejeitos femininos, que lhe dão características homossexuais, ao mesmo tempo que observamos episódios de agitação psicomotora, com agressões físicas. (...) É chamativa a conduta homossexual que está estruturada em seu funcionamento mental, pois desde a idade de 8 anos que apresenta este desvio de sexualidade, inclusive este tem sido o seu modo de vida. Apresenta trejeitos femininos, veste-se com trajes de mulher e tem companheiros eventuais no relacionamento homossexual. (...) O afeto quanto a sua situação e nas suas relações interpessoais é rígido, mas tornar-se ansioso quando se vê reprimido nas situações homossexuais, inclusive reage com episódios de agitação psicomotora. Pelos sintomas descritos acima podemos definir o examinado como portador de Esquizofrenia Paranoide e Homossexualismo. Como no presente caso examinado necessita de atendimento especializado, onde seus impulsos possam ser melhor controlados e manejados, somos de opinião, que, em caso de aplicação da 'Medida de Segurança' que esta possa ser cumprida em ambiente do tipo Manicômio Judiciário, onde as técnicas de tratamento podem auxiliá-lo em sua adequação mais adequada do que nas Casa Prisionais Comuns" (laudo psiquiátrico sobre mulher travesti, 13/Jun/1984).

No fragmento anterior, a descrição das expressões da sexualidade e de gênero é enumerada com o objetivo de estabelecer uma relação entre certas características e a necessidade da manutenção da medida de segurança. Trata-se de uma série de frases adjetivadas para enfatizar o mesmo ponto: a depravação psicológica-moral dessa pessoa na manifestação da sua sexualidade e na construção do seu gênero. Toda vez que as expressões de sexualidade e de gênero não hegemônicas se evidenciam no exame médico-legal é para afirmar certo caráter depravado e imoral do sujeito examinado. A função do exame é desqualificar as manifestações singulares desses sujeitos em prol de uma racionalidade moral já dada.

Segundo Foucault 9, constitui o que chama de duplo psicológico-ético do delito. Sua função é deslegalizar a infração cometida, prevista em seu código, para fazer aparecer o seu duplo: irregularidades fisiológicas, psicológicas, morais etc. Baseando-se nisso, o juiz assentará a sanção penal nessas condutas irregulares afirmadas como causa e origem de formação do crime. Esse mecanismo irá situar a ação punitiva do poder judiciário em um córpus geral de técnicas que se articulam visando à transformação de indivíduos. A função do perito é constituir um cenário de falhas e faltas que afirme a semelhança anterior do indivíduo com o crime cometido.

"Desde seus 16 anos, tem preferência sexual por outros homens; nesta idade passou a manter relacionamentos sexuais esporádicos, inicialmente com amigos de seu bairro. Nunca teve um relacionamento sexual ou afetivo mais fixo, as relações sendo sempre ocasionais e por prazer, jamais por dinheiro. Até os dias atuais tem esta preferência sexual, mantendo relações sexuais no presídio onde se encontra, 'fazendo aquilo que me pedem pra fazer'..." (laudo psiquiátrico sobre homem cis 4, 13/Jun/1996).

Nesse fragmento, são descritos determinados comportamentos sexuais do sujeito examinado, estabelecendo uma ligação entre a história dessa pessoa e as expressões da sexualidade e de gênero. $\mathrm{O}$ exame médico-legal não está descolado dos preconceitos existentes na sociedade, como também pode reproduzi-los discursivamente. Contemporaneamente, diferentes movimentos sociais em defesa dos sujeitos não heterossexuais e não cisgêneros problematizam o tratamento que estas pessoas recebem, quando seus direitos são revogados. Isso reforça a necessidade de se estabelecer novas políticas para além do enclausuramento desses sujeitos. 
O exame efetiva, pela reativação de categorias elementares da moralidade em um discurso específico organizado, a suposição do perigo e da perversidade do paciente judiciário ${ }^{9}$. Tal construção discursiva descreve de forma detalhada as ações do sujeito, sua história de vida, a ponto de torná-la ridícula. Reconstituem-se hábitos, disfuncionalidades familiares, falhas da personalidade anteriores ao crime. Todos esses dados são decodificados à luz do saber científico representado pelo perito. Compõe-se, assim, o cenário que permite ao juiz impor medidas corretivas que vão afastar o paciente judiciário do convívio social. Logo, o laudo não deve apenas responder se o sujeito é insano ou não, mas se este é perigoso, se é sensível a uma sanção penal e se é "readaptável".

Para Foucault 9, o discurso jurídico-psiquiátrico tem estatuto de verdade, ao mesmo tempo em que está alheio a todas as regras, especialmente as da ciência e do Direito. Na perspectiva do autor, a descrição do indivíduo e de sua história de vida organizada pelo exame médico-legal utiliza elementos discursivos que em outros campos da ciência seriam inadequados para uma redação que se considera científica. Tal escrita evidencia uma articulação discursiva particular a esses documentos. Segundo o autor, a linguagem utilizada pelos psiquiatras na produção do exame deveria desqualificá-lo como prova de verdade, mas não é o que acontece. É justamente para se evidenciar por uma aparente desqualificação que o laudo pode funcionar, no outro extremo, com uma racionalidade própria que o torna inteligível em seus próprios termos. É dessa forma que tal documento se torna eficaz. O poder de normalização efetivado pelo exame médico-legal, em sua face abjeta, infame, ubuesca, ou simplesmente ridícula, pode funcionar com todo o seu rigor em uma violenta racionalidade.

Como já abordado, o laudo psiquiátrico é um efeito do governo sobre os "desviantes" que se instaurou na sociedade, a partir da configuração de estratégias de condução da conduta que Foucault designou como biopolítica 12. É tal a configuração do poder que estabelece a governamentalidade na forma de um controle difuso sobre os fluxos da vida. As características táticas de ação dessa forma de governo são (re)produzir práticas e crenças com propósitos específicos 16.

No que tange à gestão dos "desviantes", Butler 16 centra sua análise na coexistência do poder soberano com regimes democráticos que efetiva uma reconfiguração da forma atual do Estado. Para essa filósofa, o exercício de soberania se efetiva pela limitação e suspensão da ação da lei como tática de govermentalidade. Os mecanismos médico-jurídicos são invocados e suspensos por uma soberania que produz a exclusão do "louco infrator". Desse modo, a possibilidade de existir um exame que pode decidir a prisão por tempo indefinido de alguém denota a existência um regime de governo sustentado por uma série de decisões aparentemente ilegítimas. A vida dessas pessoas é julgada como menos humana e consequentemente goza de menos direitos básicos. Essa forma de detenção indefinida funciona como parte de uma tática mais ampla para neutralizar a cidadania em nome da segurança 16 . É uma exceção naturalizada dos códigos calcada na suposição de perigo àquilo que está fora da razão moderna. Tais questões, evidentemente problemáticas, apontam a necessidade de se produzir novos valores sobre aqueles que residem às margens da norma e, consequentemente, sobre as pessoas que permanecem perpetuamente ancoradas nesse movediço terreno que circunscreve os campos do crime e da loucura.

\section{Considerações finais}

A ação da medida de segurança como sanção penal segue uma direção específica. Fundamentada na presunção de periculosidade, ela pode operar objetivamente como uma prisão perpétua para sujeitos que fogem à expectativa de normalidade. Também baseando-se em certa produção discursiva, a medida de segurança pode efetivar uma penalização da existência dos sujeitos com diagnóstico psiquiátrico que cometeram um crime. Não se trata de apenas julgar as ações delituosas por eles cometidas, mas também de antecipar um julgamento de crimes que, por ventura, possam vir a ocorrer. Trata-se, portanto, de condenar a existência da loucura como elemento central de uma concepção de anormalidade. Nesse cenário, não se estaria diante de um ser capaz de responder por suas ações, mas de alguém atestado cientificamente como irracional, louco. Com base nessa leitura, está silenciada a voz do paciente judiciário e revogados seus direitos.

O exame médico-legal tem um papel central na produção dessa exclusão. Valendo-se do discurso médico-jurídico, a medida de segurança e o laudo psiquiátrico operam uma codificação científica dos 
traços "desviantes" do paciente judiciário. Servindo como instrumento da ciência para a averiguação do perigo, o exame médico-legal se valerá de um saber sobre o corpo na injunção crime-loucura. Unindo o saber médico e o Poder Judiciário, o exame fornece os elementos patologizantes da conduta desses indivíduos que serão convertidos em infrações penais. Cada pequena irregularidade psicológica-moral será essencializada em um crime para comprovar o caráter perigo e perverso do sujeito sob análise. Detentor do conhecimento científico, o perito é legitimado pelo sistema a emitir um juízo de verdade sobre a vida do paciente judiciário. Na prática, a redação do laudo demonstra um engendramento moral investido nesse instrumento científico-legal. O corpo perigoso, atestado por esse documento, quer comprovar a existência de uma essência imoral no "louco infrator".

A violação dos Direitos Humanos, propiciada pela medida de segurança, é ainda mais gritante quando posta em contraste seus efeitos com o que se espera de uma medida de tratamento humanizado a pessoas em sofrimento mental. A Lei da Reforma Psiquiátrica preconiza o redirecionamento do modelo assistencial em saúde mental para o atendimento na rede de atenção psicossocial. Diferentemente do que propõe essa Lei, a medida de segurança objetiva tratar o "louco infrator", afirmando o perigo que este representa para si e para os outros, sem priorizar as necessidades particulares destas pessoas. Achatar sua experiência, revogar seus direitos e silenciar sua voz: esses são os efeitos dessa sanção penal na vida do "louco infrator".

Os diferentes jogos de verdade no governo do "louco infrator" constroem uma identidade atemporal e a-histórica para essas pessoas. Marcados por diferentes racionalidades, tais esquemas sustentaram a loucura como condição deficitária de acesso à realidade. Quando as expressões da sexualidade e de gênero são evidenciadas, é para acentuar essa característica do paciente judiciário. Esses constructos mantêm sua estabilidade pela presunção de que são imutáveis e inquestionáveis, escondendo que os corpos na injunção crime-loucura estão constantemente em disputa com os engendramentos do poder. O preconceito sofrido por pessoas que expressam a sexualidade ou o gênero de formas que não correspondem à cisheteronorma aponta para a necessidade de questionar o estigma que marca essas pessoas também fora dos espaços manicomiais. Nessa perspectiva, toda a intervenção na realidade não pode estar descolada de uma ação política que denuncie um possível descaso do Estado frente a essas vidas. Para isso, devem ser articuladas novas estratégias que subvertam a geografia da racionalidade, trazendo o corpo em sua capacidade de intervenção política. Questionar os valores morais que sustentam as perspectivas tradicionais de dispositivos médico-jurídicos torna-se essencial para o estabelecimento de outra relação com esses transtornos. Ir além do medo daquilo que escapa à racionalidade hegemônica é a via central para reafirmar eticamente as diferentes possibilidades de existir no mundo.

\section{Colaboradores}

W. Guimarães contribuiu com a revisão bibliográfica e a coleta e análise do conteúdo recolhido para a construção da pesquisa e redigiu o artigo. S. M. Paulon efetuou revisão crítica da literatura sobre a problemática da presunção de periculosidade e o tratamento do paciente judiciário, tecendo considerações e sugerindo alterações a respeito deste conteúdo; responsável pelo acompanhamento global e sistemático do processo de escrita. H. C. Nardi efetuou revisão crítica da literatura sobre gênero e sexualidade e contribuiu com a análise dos dados. Foi responsável pela revisão final do artigo, tecendo comentários e sugerindo alterações.

\section{Agradecimentos}

Aos profissionais que atuam cotidianamente na injunção crime-loucura em prol da Reforma Psiquiátrica. 


\section{Referências}

1. Jacobina PV. Direito penal da loucura: medida de segurança e reforma psiquiátrica. Brasília: Escola Superior do Ministério Público da União; 2008.

2. Brasil. Lei no 10.216, de 6 de abril de 2001. Dispõe sobre a proteção e os direitos das pessoas portadoras de transtornos mentais e redireciona o modelo assistencial em saúde mental. Diário Oficial da União 2001; 9 abr.

3. Diniz D. A custódia e o tratamento psiquiátrico no Brasil: censo 2011. Brasília: LetrasLivres/ Editora UnB; 2013.

4. Conselho Federal de Psicologia. Inspeções aos manicômios - relatório Brasil 2015. Brasília: Conselho Federal de Psicologia; 2015.

5. Bueno AC. O canto dos malditos. Rio de Janeiro: Rocco; 2004.

6. Carrara S. Crime e loucura: o aparecimento do manicômio judiciário na passagem do século. Rio de Janeiro: EdUERJ/São Paulo: Edusp; 1998.

7. Ibrahim EMM. Manicômio judiciário: o testemunho de um olhar vivido [Dissertação de Mestrado]. Rio de Janeiro: Pontifícia Universidade Católica do Rio de Janeiro; 2012.

8. Foucault M. História da sexualidade II: o uso dos prazeres. 8a Ed. Rio de Janeiro: Edições Graal; 1998.

9. Foucault M. Os anormais: curso no Collège de France. 2a Ed. São Paulo: WMF Martins Fontes; 2010.
10. Butler J. Problemas de gênero: feminismo e subversão da identidade. Rio de Janeiro: Civilização Brasileira; 2003.

11. Lemos FCS, Cardoso Júnior HR. A genealogia em Foucault: uma trajetória. Psicol Soc 2009; 21:353-7.

12. Foucault M. Microfísica do poder. 10a Ed. Rio de Janeiro: Edições Graal; 1992.

13. Scaramella ML. Biografias judiciárias: analisando laudos psiquiátricos de autos de processos penais. In: Koffes S, Manica D, organizadores. Vida e grafias: narrativas antropológicas entre biografia e etnografia. Rio de Janeiro: Lamparina/Faperj; 2015. p. 200-21.

14. Barros-Brisset FO. Gênese do conceito de periculosidade [Tese de Doutorado]. Belo Horizonte: Universidade Federal de Minas Gerais; 2009.

15. Reis C. (Falência familiar) + (Uso de drogas) $=$ risco e periculosidade: a naturalização jurídica e psicológica de jovens com medida de internação compulsória [Dissertação de Mestrado]. Porto Alegre: Universidade Federal do Rio Grande do Sul; 2012.

16. Butler J. Vida precaria: el poder del duelo y la violencia. Buenos Aires: Editorial Paidós; 2006. 
Abstract

This article aims to analyze how expressions of sexuality and gender emerge in the legal proceedings that determine the fate of individuals at the interface between crime and madness. The text explores the criminal proceedings against persons in mental distress that have committed crimes, or so-called "criminally insane" patients, and who are subject to security measures. Using genealogy as the methodological approach, the article analyzes the conditions underlying the source and emergence of the "abnormal", a figure produced and scrutinized by forensic medical discourse. Six court briefs were analyzed, focusing especially on the psychiatric reports pertaining to non-heterosexual and/or non-cisgender persons that were subjected to security measures. Analysis of the textual corpus indicates that the theoretical and conceptual basis for the assumptions in the security measures focuses on the forensic psychiatric report. The analysis of the forensic medical discourse points to a moral judgment of the expressions of sexuality and gender in the criminally insane patient, considered "deviant". Finally, the article signals alternatives for the production of new treatment modalities for the criminally insane patient, seeking to supplant the presumption of danger to society as a purportedly scientific concept, reviewing non-imputability as a legal device that violates the inalienable rights of individuals at the interface between crime and madness.

Deinstitutionalization; Sexuality; Gender Identity; Mental Health; Human Rights

\section{Resumen}

El objetivo de este trabajo ha sido analizar la forma en la que surgen expresiones de sexualidad $y$ género en procedimientos judiciales, que definen las sentencias a sujetos durante los trámites judiciales relacionados con casos de crimen-locura. Para tal fin, investiga procesos penales en relación con personas que padecen enfermedades mentales y que cometieron crimenes, denominados pacientes judiciales, a quienes se les otorgan medidas de seguridad. Utilizando la genealogí como aporte metodológico, se adentra en las condiciones de procedencia y emergencia de lo "anormal", figura creada y escudriñada dentro del discurso médico-jurídico. Se analizaron seis autos judiciales, centrándose principalmente en los dictámenes psiquiátricos de personas no heterosexuales y/o no cisgénero, a quienes se les otorgó medidas de seguridad. El análisis del corpus indica que la base teóricoconceptual, en la que se basan los presupuestos de las medidas de seguridad, se concentra en el dictamen psiquiátrico. El análisis del discurso médicojurídico apunta a una valoración moral de las expresiones de la sexualidad y de género del paciente judicial, considerado como "desviado". Finalmente, se señalan alternativas para la producción de nuevos modelos de tratamiento en el caso del paciente judicial, que buscan superar la ficción de la presunción de peligrosidad, como base presuntamente científica, revisando la inimputabilidad como dispositivo jurídico que viola derechos inalienables de los individuos en los procedimientos judiciales relacionados con casos de crimen-locura.

Desinstitucionalización; Sexualidad; Identidad de Género; Salud Mental; Derechos Humanos
Recebido em 14/Out/2017

Versão final reapresentada em 08/Mar/2018

Aprovado em 23/Mar/2018 